\title{
Cultivar Name Registration at the Arnold Arboretum 1995
}

\author{
Stephen A. Spongberg ${ }^{1}$ \\ The Arnold Arboretum of Harvard University, 125 Arborway, Jamaica Plain, MA 02130-3519, USA
}

The Arnold Arboretum of Harvard Univ. continues to serve as International Registration Authority for cultivar names in 11 genera of ornamental woody plants, and the following notes pertain to cultivar names that have been registered since the last list was prepared. The 11 genera include Chaenomeles, Cornus, Fagus, Forsythia, Gleditsia, Lantana, Malus (ornamental species only), Philadelphus, Pieris, Ulmus, and Weigela. The following five cultivar names have been registered during the past year.

Cornus kousa 'Wolf Eyes'. Registered 5 Apr. 1995. The name Cornus kousa 'Wolf Eyes' has been registered by Michael R. Patterson, Jr., and Amy Wood of Manor View Farm, 15601 Manor Rd., Monkton, MD 21111. This new cultivar with variegated leaves was previously described in an article by R.A. Jaynes, A.J. Brand, and J. Arnow in the American Nurseryman [178(10):40-47; 1993].

Gleditsia tricanthos 'Prairie Silk'. Registered 14 Apr. 1995. This selection of Gleditsia tricanthos has a habit with nearly horizontal branches that are unarmed with thorns, and the plants have proven to be reliably winter hardy in U.S. Dept. of Agriculture zone 3. 'Prairie Silk' originated at the Fred Sanford Research Farm near Portage la Prairie, Man., Canada, and the name was registered by Rick Durand of

${ }^{1}$ Horticultural Taxonomist.
Prairie Shade Consulting Services, 89 Wilkinson Crescent, Portage la Prairie, MB R1N 1A7, Canada.

Malus 'Spring Bride'. Registered 31 Dec. 1995. The cultivar name 'Spring Bride' has been registered by Campbell G. Davidson of the Morden Research Centre, Agriculture and Agri-Food Canada, Unit 100-101, Route 100, Morden, MB R6M 1Y5, Canada. 'Spring Bride' is a rounded-crowned, hardy, double-flowered white crabapple adapted for growth in the northern Great Plains and Canadian prairies. It has been released from the Morden Research Centre breeding program, and an article by Davidson describing this new selection is to be published in the near future.

Philadelphus 'Blizzard'. Registered 1 Dec. 1995. The cultivar name 'Blizzard' was registered by Campbell G. Davidson of the Morden Research Station, Agriculture Canada, and the new selection of Philadelphus lewisii has been described by Davidson and John Wallace in an article that appeared in the Journal of Environmental Horticulture (12:241, 242; 1994).

Weigela subsessilis 'Canary'. Registered 9 May 1995. Weigela 'Canary' produces masses of clear yellow flowers that are maintained as yellow until late senescence. This characteristic is unlike most individuals of $W$. subsessilis, in which the flowers quickly develop a brick-red color after anthesis. This new cultivar was selected, named, and registered by Richard W. Lighty, Mt. Cuba Center, Greenville, DE 19807. 